\title{
The removal of lead by natural zeolite
}

\author{
Wawan Budianta*, Adinda Ardiana, and Norma Dian Andriyani \\ Department of Geological Engineering, Universitas Gadjah Mada, Indonesia
}

\begin{abstract}
This study aimed to evaluate the ability of natural zeolite samples obtained from Gunungkidul, Yogyakarta, Indonesia in the removal of lead $(\mathrm{Pb})$ in solutions. This study included mineralogical characterization as well as a batch test in the laboratory with parameters including grain size, the mass of natural zeolite sample, $\mathrm{pH}$, and initial concentration of the solution. The results of mineralogical characterization showed that the natural zeolite sample have varied constituent on mineral components and relatively have high cation exchange capacity (CEC). The results of the batch test showed that the adsorption behavior depends on the mass of the zeolite sample which the increasing of the sample mass will increase the adsorption capacity. The results of the following batch testing showed that the variations in grain size had a limited effect on the adsorption capacity and the effect of the $\mathrm{pH}$ of the solution being a significant parameter. The results of the following batch test also showed that the increasing initial concentration of $\mathrm{Pb}$ solution caused a decrease in adsorption capacity. In general, natural zeolite samples in the study area have sufficient adsorption capacity as adsorbent material for $\mathrm{Pb}$ solution.
\end{abstract}

\section{Introduction}

In the era of industrialization today, the waste produced by industrial activity is increasing, especially for waste containing heavy metals. Heavy metal waste is usually produced by industrial and mining activities as well as domestic $[1,2]$. Thus, the processing of heavy metal waste is needed in the context of environmental conservation. Processing heavy metal waste from liquid waste is a challenge in waste management for the past two decades. During this period, a lot of research was carried out by utilizing abundant natural materials as a medium for managing heavy metal waste, such as carbon, cocopeat, clay lignite and natural zeolites [3, 4]. Natural zeolites are usually found as a result of low temperature alteration in various types of rocks, but usually predominantly occurs in volcanic and sedimentary rocks [5]. The purpose of this study is to investigate the characteristics of natural zeolite adsorption on lead $(\mathrm{Pb})$ in solution by conducting a batch test. The batch test was used because it offers the advantage of a more straightforward design and widely used in the study of adsorption both in the laboratory and more massive scale [6]. The natural zeolite sample was obtanined from the Tegalrejo, Gedangsari, Gunungkidul, Yogyakarta. There was a previous study on the use of natural zeolite in this study area. However, the information was limited to obtain a comprehensive understanding of the utilization of this material for environmental remediation purposes [7, 8, 9]. The regional geological data indicated that this natural zeolite is part of the Kebo-Butak Formation, which is rich in layers of green colored tuffs, and in the study area this unit is dominated by sand stone tuffs with silt stones tuff inserts which have greenish cream-gray color $[10,11]$.

\section{Materials and methods}

Natural zeolite samples in this study site were not activated, while the mineralogical compositions were analyzed using a polarizing microscope and X-ray diffraction (XRD). The Cation Exchange Capacity (CEC) was measured by the ammonium acetate method $(\mathrm{pH}=$ 7.0), while the specific surface area was measured using the Brunauer-Emmett-Teller (BET) method and the analysis of the concentration of $\mathrm{Pb}$ solution was carried out using inductively coupled plasma atomic emission spectroscopy (ICP-AES). The batch test was conducted by crushing natural zeolite samples into grains then sieved for 15 minutes. Furthermore, each grain size was weighed with each sample mass of $3.7 \mathrm{~g}, 7.5 \mathrm{~g}$, and $15 \mathrm{~g}$ in a constant volume $(100 \mathrm{~mL})$ of $\mathrm{Pb}$ solution, at concentrations of 20,400 , and $800 \mathrm{ppm}$. The stirring was conducted in $15,30,45,60,120,180$, and 240 minutes for each sub parameter using a magnetic stirrer at a temperature of $30^{\circ} \mathrm{C}$ [12]. The percentage of metal adsorption (\%) was calculated using the following equation:

$\%$ adsorption $=(\mathrm{Ci}-\mathrm{Cf}) .100 / \mathrm{C}$

in which:

$\mathrm{Ci}$ : initial concentration of the solution

Cf: final concentration of the solution

Furthermore, the parameter variations used in batch test are sample grain size $(0.15 \mathrm{~mm}, 0.71 \mathrm{~mm}$ and $1.98 \mathrm{~mm})$,

\footnotetext{
*Corresponding author: wbudianta@ugm.ac.id
} 
sample mass (3.7 gr, 7.5 gr and $15 \mathrm{gr}$ ), $\mathrm{pH}$ of the solution $(2,5,3,5$ and 4,5), and the concentration of $\mathrm{Pb}$ solution $(20,400,800 \mathrm{ppm})$. This variation was conducted to simulate and obtain the optimum condition of the adsorption process based on another study [12]. Then, the batch test was conducted using a magnetic stirrer for 240 minutes, at a temperature of $25^{\circ} \mathrm{C}$ at $300 \mathrm{rpm}$.

\section{Result and discussion}

\subsection{The characteristics of natural zeolite sample}

The results of microscopic observation on natural zeolite sample can be seen in table 1 and showed that the sample, in general contained glass, crystal and rock fragments as main materials, of which the proportion of glass is abundant, but crystal and rock fragments were found to be less than $10 \%$ and the sample was classified as vitric tuff [13]. In general, glass as a constituent component of natural zeolites which has been changed to zeolite minerals but from conditions both physically and microscopically indicate that zeolite material contained impure consists of not only natural zeolites but also a few percent impurity minerals such as clay minerals, plagioclase and quartz are present. This result is confirmed by several other studies that show that, naturally, the presence of natural zeolites around the study area will have heterogeneity of varied mineralogical contents $[14,15,16,17,18,19]$. The XRD analysis results showed the presence of zeolite minerals and clay minerals. Clinopilolite and mordenite are the dominant zeolite minerals, and other minerals are also present, such as quartz, plagioclase, illite, smectite. This result is confirmed by several other studies that show that naturally, the presence of natural zeolites around the study area will have heterogeneity of varied mineralogical contents $[14,18,19]$. The results of the CEC analysis show that value is relatively high but in general it shows that this value is relatively small when compared to other natural zeolites that have been studied by another researcher [20]. This might be due to differences in the percentage of zeolite minerals, in this case clinopilolite and mordenite, as well as other impurity minerals such as quartz, plagioclase and feldspar which will reduce the value of CEC, as confirmed by other researchers [21, 22].

Table 1. Summary of mineralogical composition and CEC of the studied natural zeolites

\begin{tabular}{c|c}
\hline Component & Value (\%) \\
\hline Mordenite & 18.12 \\
\hline Clinipilolite & 5.66 \\
\hline Illite & 4.35 \\
\hline Smectite & 2.38 \\
\hline Quartz & 5.71 \\
\hline CEC $(\mathrm{meq} / 100 \mathrm{~g})$ & 43.2 \\
\hline Specific surface area $\left(\mathrm{m}^{2}\right)$ & 29.8 \\
\hline Volcanic glass & 81 \\
\hline Rock fragment & 4 \\
\hline Crystal & 2
\end{tabular}

\subsection{Batch test}

\subsubsection{The effect of grain size}

The experiments were carried out using three grain sizes of zeolite samples with a diameter of $<0.15,0.15-0.701$, and $0.701-1.98 \mathrm{~mm}$ which were then contacted with $\mathrm{Pb}$ solution on a magnetic stirrer for 240 minutes. The results of the experiment can be seen in Figure 1 which shows that samples with sizes $<0.15 \mathrm{~mm}$ have the highest initial adsorption capacity. However, after 45 minutes, the adsorption capacity tends to be constant with a value of $43 \%$ until reaching the equilibrium condition. In the sample size of $0.15-0.701 \mathrm{~mm}$, it showed an increase in adsorption at 45 minutes with an adsorption capacity of $42 \%$ until reaching the equilibrium condition and in the sample size of $0.701-1.98 \mathrm{~mm}$, there was also significant increase in adsorption until reaching the equilibrium condition with a capacity value of adsorption of $45 \%$. Generally the increasing of grain size will raise the adsorption value accordingly.

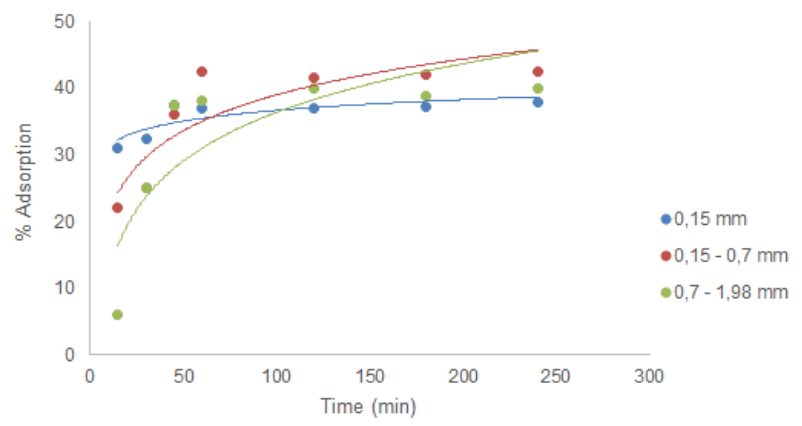

Fig. 1. The effect of grain size on adsorption capacity.

However, as contact time increased to the equilibrium condition, the sample sized $0.15-0.701 \mathrm{~mm}$ showed a decrease in the level of metal ion adsorption. In theory, the adsorption rate will be proportional to the specific surface area [23]. Particles that have smaller diameters will have a larger specific surface area and a higher adsorption rate and only less time are required to reach the equilibrium condition. This is because smaller particles have the accessibility of metal ions by diffusion of shorter ion pathways. However, in this experiment, the sample grain size was not too significant in having an effect on the value of adsorption capacity, which also found by another study [24]. Thus, it can be concluded that the increasing specific surface area is not the only mechanism but also causes an increase in adsorption capacity. The difference between the percentage increases in adsorption on grain size increase can be explained as ion exchange participation accompanied by external or internal surface adsorption [25]. In this case, the porous material, the internal surface area plays a greater role than the external surface. Therefore, in conducting the test using grain size, an increase in the external surface area has a limited effect on the value of the adsorption capacity. 


\subsubsection{The effect of sample mass}

The effect of sample mass was investigated in the experiment by using three natural zeolite samples of 3.7 gr, $7.5 \mathrm{gr}$ and $15 \mathrm{gr}$ which were contacted with Pb solution in a magnetic stirrer at $400 \mathrm{ppm}$. The adsorption value is shown in Figure 2, which shows that increasing the sample mass, will increase the adsorption rate. In the 3.7 gr sample, the percentage of adsorption was at the equilibrium condition of $15 \%$, a $7.5 \mathrm{gr}$ sample at $20 \%$ and a $15 \mathrm{gr}$ sample at $43 \%$ respectively. In general shows that the raising of the sample mass will increase the value of the adsorption capacity

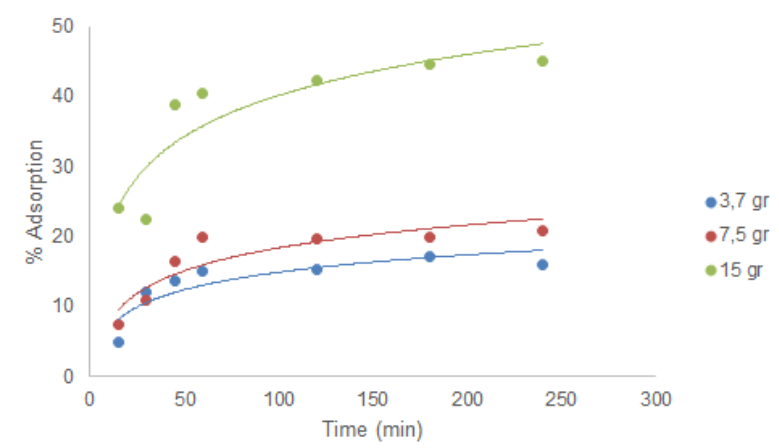

Fig. 2. The effect of sample mass on adsorption capacity.

The data in figure 2 shows that the sample 15 gr has a percentage of adsorption capacity of $43 \%$ because the sample has a large surface area, then the total surface area of zeolites is the accumulation of the pore surface area and canals making up the zeolite. In addition, increasing the mass of the sample will effect the cation exchange sites because of the greater surface area [12]. A similar batch test by other researchers showed an adsorption capacity value of up to $85 \%$, but this occurs because the natural zeolite sample used had a high clinoptilolite and mordenite content up to $70 \%$ and a CEC value of 134 meq/100 gr [25].

\subsubsection{The effect of $\mathrm{pH}$ solution}

In this experiment, the effect of the $\mathrm{pH}$ of the solution was investigated and the results of the experiment can be seen in figure 3, where the relationship between the value of the percentage of adsorption to the contact time in the $\mathrm{pH}$ range of solution 2.5 to $\mathrm{pH} 4.5$ indicates that the value of the maximum adsorption capacity occurs at the $\mathrm{pH}$ of the solution $\mathrm{pH} 4.5$ with an adsorption value of $22 \%$ when it reaches the equilibrium condition at 240 minutes. The experiment results showed that the cation adsorption was mostly complete by the $\mathrm{pH}$ of the solution of 4.5. Anion adsorption is carried out by the $\mathrm{pH}$ of the solution which has a low value in $2.5 \mathrm{pH}$ solution with adsorption at the equilibrium condition of $15 \%$. The $\mathrm{pH}$ of the solution is an important parameter that effects the adsorption process. The $\mathrm{pH}$ solution has a significant impact on the removal of heavy metals by zeolites which can affect metal speciation, zeolite integrity or mineral surface properties and also $\mathrm{H}+$ ions which are considered competitive in ion exchange. The three solutions with different $\mathrm{pH}$ showed that the higher the $\mathrm{pH}$ of the solution or the more neutral the $\mathrm{pH}$ of the solution, the greater the competition in adsorbing cation capacity. In the high acid levels, with a $\mathrm{pH}$ of 2.5 , some functional groups became protected and acted positively because of the addition of +1 charge resulting in reduced attraction between the metal and adsorbent so that the $\mathrm{H}+$ charge competes with the $\mathrm{Pb}$ ion to fill the surface area which causes the adsorption capacity to be lower, whereas at $\mathrm{pH} 4.5$ the deprotonization of functional groups occurred and acted negatively to adsorp heavy metals because the value of $\mathrm{H}+$ ion concentration decreased with increasing $\mathrm{pH}$ of the solution, so that the higher the $\mathrm{pH}$ of the solution, the higher the adsorption capacity and becomes more stable [24].

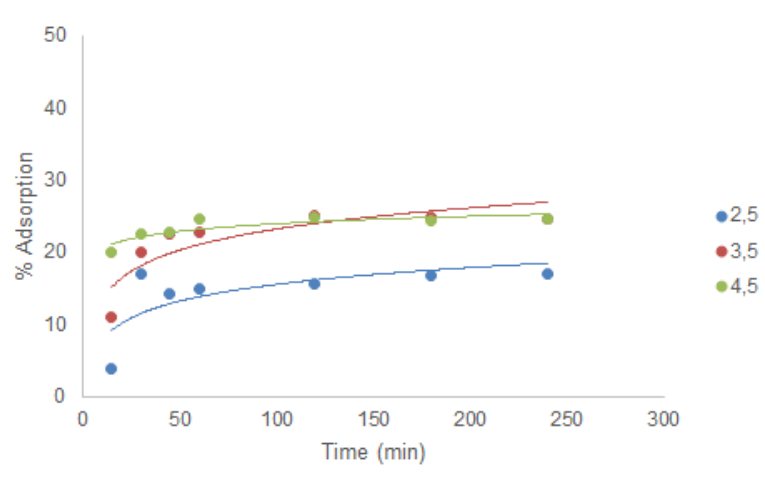

Fig. 3. The effect of $\mathrm{pH}$ solution on adsorption capacity.

The adsorption capacity increased when the initial $\mathrm{pH}$ solution was added from the $\mathrm{pH}$ of the solution 3.5 to 4.5, but the adsorption performance in the sample was almost unchanged or only slightly increased in percentage. The lowest adsorption value was obtained at the $2.5 \mathrm{pH}$ solution and might be due to increased initial competition for the filling of the adsorption are by $\mathrm{H}+$ which then the site was filled by certain species [25]. Another reseacher also conducted an experiment using zeolite samples to adsorb $\mathrm{Pb}$ and $\mathrm{Ni}$ solutions with a pH of 5 and 6 [26]. The results showed that metal absorption was more effective at $\mathrm{pH} 6$ or close to neutral $\mathrm{pH}$ with metal adsorbing reaching $90 \%$ due to the deprotonization of functional groups and negative action which attracted heavy metals because of the value of $\mathrm{H}^{+}$ion concentration decreased with increasing $\mathrm{pH}[27,28,29]$.

\subsubsection{The effect of initial concentration}

The effect of the initial concentration of the solution was investigated by contacting zeolite samples with a mass of 3.7 grams with a grain size of $0.15-0.71 \mathrm{~mm}$ with a $\mathrm{Pb}$ solution ranging from $20 \mathrm{ppm}$ to $800 \mathrm{ppm}$ concentrations. The results of the experiment can be seen in Figure 4 and show that there is a decrease in the value of the adsorption capacity as the concentration of the solution increases. At a concentration of $20 \mathrm{ppm}$ shows an adsorption capacity value of $45 \%$, while the $400 \mathrm{ppm}$ concentration has a value of $42 \%$ and the $800 \mathrm{ppm}$ concentration shows a decrease in adsorption capacity of $25 \%$. Figure 4 shows that the maximum adsorption capacity value is at an initial 
concentration of $20 \mathrm{ppm}$. This can be explained that the efficiency of the adsorption capacity value decreases with increasing concentration of the solution. Higher solution concentrations will have more metal ions contained in the solution by producing more metal ions that must be adsorbed and have a fixed or limited amount and at certain metal concentrations will become depleted and saturated.



Fig. 4. The effect of initial concentration on adsorption capacity.

This result shows that an increase in the concentration of the solution will only cause a decrease in the value of the adsorption capacity because the active site has been occupied, so more metal ions will be left in the solution after adsorption. The increase in metal ion concentration causes an increase in the adsorption value at a certain point until reaching saturation [24].

\section{Conclusion}

Natural zeolite in the study area is part of volcanic rock which is dominated by glass minerals altered to zeolite minerals that are dominated by mordenite and clinoptilolite types. In addition to zeolite minerals, other minerals were also present such as clay minerals, plagioclase, and quartz. This is maybe to be the cause of the adsorption rate of zeolite samples in this study was quite low. The results of the batch test showed that the parameters of grain size, sample mass, initial $\mathrm{pH}$ solution and the concentration of the solution had an effect on the adsorption capacity of the natural zeolite sample. Tentative remarks of this study conclude that the optimum value of removal capacity related to the natural zeolite characteristic may be reached by increasing the zeolite mineral content and upgrade internal surface area. Hence, for future works for activation of natural zeolite needs to be done to increasing the adsorption capacity of the sample.

Authors thank to Hinode Laboratory, Tokyo Institute of Technology for supporting of laboratory analysis.

\section{References}

1. F. L. Fu, Q. Wang, J. Environ. Manage, 92, (2011)

2. M. A. Barakat, Arab. J. Chem., 4, (2011)
3. S. E. Bailey, T.J. Olin, R.M. Bricka, D.Adrian, Water Res. 33, (1999)

4. S. Babel, T.A. Kurniawan, J. Hazard. Mater, 97 (2003)

5. D. L. Bish, D.W. Ming (eds.) Natural zeolites: Occurrence, properties, applications (2001)

6. I. Porro, M.E. Newman, F.M. Dunnivant, Environ. Sci. Technol., 34(9), (2000)

7. W. Budianta, N.D. Andriyani, A. Ardiana, I.W. Warmada, Environ. Earth Sci., 79, 1-1 (2020)

8. W. Budianta, A. Ardiana, IOP Conference Series: Earth and Environmental Science, 451(1), 012025 (2020)

9. W. Budianta, A. Ardiana, N.D. Andriyani, F.L. Fahmi, F. L., IOP Conference Series: Earth and Environmental Science, 479(1), 012020 (2020)

10. I. Sudarno Surono, B. Toha, Geological map of Surakarta - Giritontro sheet in scale of 1:100.000. P3G, Bandung, Indonesia (1992)

11. W. Rahardjo, The $12^{\text {th }}$ Annual Meeting of the Association of Indonesian Geologists (1983)

12. T. Motsi, N.A. Rowson, M.J.H. Simmons, Int. J. Miner. Process, 92(1-2) (2009).

13. F. J. Pettijohn, Sedimentary Rocks, 2nd edition (1957)

14. A. Idrus, A.D Titisari, R. Sudiyo, R. Soekrisno, $2^{\text {nd }}$ IASME/WSEAS International Conference on Geology and Seismology (2008)

15. S. Yuminti S, (2005), Jurnal Saintifika Gadjah Mada, 2 (2005). In Bahasa

16. D. Wintolo Widiasmoro, Dinas Pertambangan DIYJurusan Teknik Geologi FT. UGM, (in Bahasa) unpublished. (2000).

17. W. Wilopo, S.N Haryono, D.P.E Putra, I.W. Warmada, T. Hirajima, J. SE Asian Appl. Geol., 2 (2010)

18. L. Effendi, Undergraduate thesis Department of Geological Engineering, Universitas Gadjah Mada (in Bahasa) unpublished. (2010).

19. I. A. Fatkhiandari, Undergraduate thesis Department of Geological Engineering, Universitas Gadjah Mada (in Bahasa) unpublished (2011)

20. M. Moshoeshoe, M.S Nadiye-Tabbiruka, V. Obuseng, Am. J. Mater. Sci, 7 (2017)

21. A. Filippidis, N. Kantiranis, M. Stamatakis, A. Drakoulis, E. Tzamos, Bull. Geol. Soc. Greece, 40 (2007)

22. K. Babak, A.A Rahim, S.A Wahid, S.K Balasundram, M. Afyuni, Malays. J. Soil. Sci. 17 (2013)

23. L.W. Petersen, P. Moldrup, O.H. Jacobsen, D.E. Rolston, Soil. Sci. 161(1) (1996)

24. M.M. Ibrahimi, A.S. Sayyadi, Int. J. Geol. Agric. Environ. Sci., 3 (2015)

25. A.H. Oren., A. Kaya (2006) J. Hazard. Mater. 131 (2006)

26. C. Cabrera, C. Gabaldon, M. Paula J. Chem. Technol. Biotechnol, 80 (2005)

27. A.H.H. Ali, R. El-Bishtawi, J. Chem. Technol. Biotechnol., 69 (1997) 
28. A. Ardiana, Undergraduate thesis Department of Geological Engineering, Universitas Gadjah Mada (in Bahasa) unpublished. (2010)
29. N.D. Andriyani, Undergraduate thesis Department of Geological Engineering, Universitas Gadjah Mada (in Bahasa unpublished). (2010) 